\title{
A INTERDISCIPLINARIEDADE NA EDUCAÇÃO À DISTÂNCIA SUPERIOR EM CURSOS DE GRADUAÇÃO NA ÁREA DA SAÚDE
}

\author{
CURITIBA/PR JULHO/2018
}

\author{
IVANA DE FRANÇA GARCIA - Uninter - ivana.g@uninter.com \\ VERA LUCIA PEREIRA DOS SANTOS - Uninter - vera.s@uninter.com \\ IZABELLE CRISTINA GARCIA RODRIGUES - Uninter - izabelle.r@uninter.com \\ RODRIGO BERTÉ - Uninter - rodrigo.b@uninter.com \\ IVANA MARIA SAES BUSATO - Uninter - ivana.bu@uninter.com
}

\author{
Tipo: Relato de Experiência Inovadora (EI) \\ Categoria: Conteúdos e Habilidades \\ Setor Educacional: EDUCAÇÃO SUPERIOR
}

\begin{abstract}
RESUMO
A interdisciplinaridade é um mecanismo de aprendizagem de abordagem e tratamento de duas ou mais disciplinas. Na prática profissional se torna frequente a utilização da interdisciplinaridade ao estabelecer uma relação de método, análise e interpretação de conteúdos para a resolução de determinados casos. Por isso, a exigência advinda do mercado de trabalho sugere que as instituições formem profissionais com tal habilidade e entendendo a necessidade desta múltipla visão. Para atender essa nova demanda e realidade atual, os professores que atuam nos cursos superiores de tecnologia da área da saúde, de uma instituição de ensino superior na modalidade a distância, optaram pela disponibilização de estudos de casos aos discentes dentro desta nossa perspectiva. Para que os alunos pudessem responder o "case" era preciso obter conhecimento das duas disciplinas que integram o módulo. A atividade não possuía caráter avaliativo, mas os pesquisadores relataram a importância da execução da atividade para o desenvolvimento desse pensamento integrador. $O$ presente estudo objetivou verificar se os alunos conseguiriam fazer a integração dos conhecimentos, $e$ elaborar uma solução para a situação exposta, utilizou-se a metodologia de relato de caso. Resultados apontaram que dos 1.614 alunos que tinham acesso a atividade 36,3\% (587) dos alunos responderam a atividade, com alto número de assertividade (100\%, 85\% e 74\%). Por fim, verificou-se que os alunos ao realizarem a atividade, que compõe as unidades curriculares (UC) estudadas, estão conseguindo estabelecer uma conexão entre os vários saberes e apresentar soluções eficientes que buscam o relacionamento a mais de uma UC.
\end{abstract}

Palavras-chave: Interdisciplinaridade. Estudo de caso. Educação 


\section{INTRODUÇÃO}

$\mathrm{Na}$ prática profissional para resolver os problemas, conflitos e situações cotidianas é preciso que o profissional seja capaz de unir conhecimentos adquiridos ao longo de sua formação para que se possa dar a resolubilidade adequada para um determinado cenário. Para que o profissional possa fazer essa conjuntura de assuntos, faz-se necessário que ele tenha aprendido fazer essa interligação, o que invariavelmente é estimulado durante a sua vida acadêmica. Isso pode ser ministrado de três formas diferentes: com a multidisciplinaridade, quando abordam conteúdos variados, mas sem a inter-relação deles, ou com a interdisciplinaridade, quando há uma junção de determinadas disciplinas ou ainda com a "transciências", um tópico além da interdisciplinaridade, pois é a junção dos conteúdos. Segundo Vieira, et al. (2017) a transciência possibilitaria a realização de uma "análise isomórfica entre áreas do saber " e que isso seria "extremamente oportuno e útil". Para os autores supracitados, as unidades curriculares (UC) como matemática, computação e outras afins, "deveriam ser emancipados de uma única classe de estudos de casos".

Visando a interdisciplinaridade os professores que atuam em cursos da modalidade à distância, da área da saúde de uma Instituição de Ensino Superior, situada no Município de Curitiba, Paraná, optaram por trabalhar com "Estudos de casos". Essa atividade foi elaborada de forma que integrasse as duas disciplinas que compunham a fase que ocorreu durante o período de 26/02/2018 a 07/04/2018. Os estudos de casos tinham o intuito de transcender o aluno para uma situação prática, cotidiana na vida profissional, a qual ele precisaria utilizar o conhecimento obtido nas duas disciplinas da fase, para resolver o problema exposto pelos professores. A atividade não possuía caráter avaliativo, contudo, os alunos foram estimulados a participar devido a importância da criação de um pensamento integrador no mercado de trabalho.

Costa e Loureiro (2017) afirmam que existem duas formas de pensar: a crítica e a dialética. A primeira é considerada, pelos autores, a forma correta de se pensar, já a segunda é quando não há uma intervenção do ator, apenas a participação de mero observador. Ao introduzir o estudo de caso pretende-se que os alunos tornem-se pensadores críticos, avaliando todas as possibilidades que envolvem a situação relatada e assim possam encontrar a melhor saída.

Diante do exposto, o objetivo deste estudo é verificar se os alunos conseguiram fazer a junção dos conhecimentos e elaborar uma solução para a situação exposta a eles.

\section{METODOLOGIA}


O presente estudo utiliza a metodologia de relato de experiência, são descritos a experiência dos pesquisadores na disponibilização da estratégia de estudo de caso interdisciplinar. Houve participação indireta dos alunos de cursos superiores tecnológicos (CST) da área da saúde de uma instituição de ensino superior, que atua predominantemente com cursos de educação a distância.

Os cursos que integraram esse estudo foram: CST em Gestão hospitalar, CST em Saúde pública e CST em Gestão em Vigilância em saúde. As disciplinas utilizadas para trabalhar a interdisciplinaridade foram:

- Comunicação Organizacional/Sistema de Informação Gerencial (utilizado nos três cursos mencionados)

- Hotelaria Hospitalar/Marketing Hospitalar (utilizado apenas no curso de CST Gestão Hospitalar)

- Gestão de Recurso Humanos/Gestão de Contratos e Convênios em serviços de saúde (utilizado apenas no curso de CST em Gestão em Saúde Pública).

Para o primeiro grupo de disciplinas 812 alunos estavam vinculados a oferta e por isso tiveram acesso ao "case" elaborado pelos professores/tutores dos cursos. Já no segundo grupo de disciplinas havia 480 alunos e o último grupo contava com 322 discentes atrelados as disciplinas e consequentemente com acesso ao estudo de caso. Totalizando 1.614 alunos.

A atividade ficou disponível para que os alunos pudessem acessá-la e respondê-la no período de $05 / 03$ a 30/03/2018. Houve por parte dos tutores a solicitação para realização das atividades, bem como, foi dada ênfase à sua importância.

\section{DESENVOLVIMENTO}

O mercado de trabalho tem se mostrado cada vez mais exigente, o que impacta na formação dos profissionais. Atualmente, as IES buscam formar profissionais mais críticos e competentes para atender tal demanda. A formação desarticulada e fragmentada existente em modelos pedagógicos de anos passados não se adequam a atual realidade. Esse modelo de ensino era visto como multidisciplinar, onde as unidades curriculares eram estudadas isoladamente, cada uma em um momento único, sem o vínculo com demais unidades temáticas (PIRES, 1998). É inconcebível que nos dias atuais os profissionais atuem considerando uma única área, sem considerar a influência das demais. O mundo hoje possui várias múltiplas faces e isso faz com que o objeto alvo seja avaliado nessa mesma perspectiva. 
Buscando formar profissionais mais capacitados para o mercado de trabalho as IES desenvolvem atividades que façam a inter-relação das disciplinas, por meio de processos pedagógicos de multidisciplinaridade, interdisciplinaridade ou transdisciplinaridade. Schwartzman, et al. (2017) conceitua a multidisciplinariedade como,

(...) multidisciplinaridade concerne ao estudo de objeto por várias disciplinas simultaneamente, significando, na prática, a interpretação do mesmo objeto de estudo a partir do seu modo particular de atuação em cada disciplina (por exemplo, o aborto da perspectiva da medicina, do direito, filosofia, teologia, entre outras). A interdisciplinaridade, por sua vez, refere-se à transferência de métodos de uma disciplina a outra, por exemplo, as diferentes disciplinas citadas analisando integradamente o problema, dialogando entre si. Já a transdisciplinaridade diz respeito ao que se situa entre as disciplinas, ou seja, entre os limites de suas fronteiras, tendo como um de seus imperativos a unicidade do conhecimento; essa interpretação ultrapassa as disciplinas aqui adotadas como referência, proporcionando novo tipo de olhar, mais orgânico e integrado à questão analisada (SCHWARTZMAN, et al., 2017, p. 537)

Já a interdisciplinaridade, modelo utilizado por grande parte das Instituições de Ensino superior nos dias atuais, utiliza-se da junção de duas ou mais unidades curriculares. Esse modelo desperta no discente a noção de que todos os conteúdos ministrados em um curso estão interligados (ROQUETE, et al. 2012). Xavier et al (2017, p. 374 apud JAPIASSÚ; MARCONDES, 2006) conceitua a interdisciplinaridade como

(...) um método de pesquisa e de ensino suscetível de fazer com que duas ou mais disciplinas interajam entre si, esta interação podendo ir da simples comunicação das ideias até a integração mútua de conceitos, da epistemologia, da terminologia, da metodologia, dos procedimentos, dos dados e da organização da pesquisa. [...] O objetivo utópico do método interdisciplinar, diante da especialização sem limite das ciências, é a unidade do saber(XAVIER, et al (2017, p. 374 apud JAPIASSÚ; MARCONDES, 2006)

Xavier et al. (2017) afirmam ainda que a interdisciplinaridade é a junção de conhecimentos que por fim tornam-se antidisciplinares, pois, ao tempo que se une variadas áreas de conhecimento acaba-se por destituir a unidade curricular. Outro ponto de destaque colocado pelos autores supracitados é a dificuldade do professor tradicional romper o paradigma metodológico aplicado até aquele momento e passar a estabelecer relações entre variados saberes. Contudo, esse processo de integração faz-se necessário, visto que, a formação clássica disciplinar não atende mais a demanda contemporânea.

Farias et al (2018) cita que a interdisciplinaridade é na prática a interprofissionalidade, pois na prática do labor há uma inter-relação de conhecimentos e habilidades que devem ser utilizadas em conjunto. Mas, assim, como posto por Xavier et al (2017), também verificaram que no cotidiano profissional alguns colaboradores da área da saúde demonstraram uma certa dificuldade em realizar determinadas tarefas por não conseguir fazer uso da interdisciplinaridade. 
Há ainda um modelo onde as unidades curriculares são vistas como um todo da grade curricular, a transdisciplinaridade, onde as ciências são envolvidas de tal forma que não há diferenciação entre as disciplinas (matemática, física, etc.), mas sim um conteúdo de ciências lógicas, onde todos estas unidades curriculares serão vistas juntas, como uma única disciplina. Nesse modelo o que é visto é um determinado tema a ser discutido e dentro dele serão apresentadas todas as ciências que o envolvem (ROQUETE, et al. 2012).

Dessa forma, pode-se afirmar que a interdisciplinaridade é um modelo de aprendizagem intermediário entre a multidisciplinaridade, onde várias as unidades curriculares não se envolvem diretamente, e a transdisciplinaridade, onde há um envolvimento direto entre as unidades curriculares.

Buscando estimular os alunos a criarem o hábito de fazer tal relação quando estiverem inseridos no mercado de trabalho, os professores de uma IES, situada em Curitiba Paraná, dos Cursos Tecnológicos de Graduação da área da saúde optaram por disponibilizar aos seus alunos estudos de casos (cases) que estimulem o pensamento integrador entre as várias áreas de conhecimento e os resultados apontaram que dos 1.614 alunos que tinham acesso a atividade apenas 36,3\% (587) dos alunos responderam a atividade, sendo que o curso de CST em gestão hospitalar apresentou o maior índice de atividades realizadas (62\%), seguido do curso de CST em Gestão em Saúde Pública (45\%), conforme demonstrado na tabela 1.

Com relação a resposta esperada, pode-se verificar que os alunos demonstraram maior facilidade de integração entre os conhecimentos nas disciplinas de comunicação organizacional e sistema de informação gerencial, pois, $100 \%$ dos alunos assinalaram a resposta considerada como correta. O case apresentado nas disciplinas de Hotelaria hospitalar e Marketing hospitalar foi o segundo com maior índice de respostas corretas (85\%), já o case apresentado no curso de saúde pública para as disciplinas de Gestão de contratos e convênios em serviços de saúde e Gestão de recursos Humanos foi onde os alunos demonstraram maior dificuldade de integração de saber para resolver a situação apresentada (74\%).

Tabela 1: Índice de realização da atividade e de respostas esperadas 


\begin{tabular}{|c|c|c|c|c|}
\hline Cursos & Disciplinas & $\begin{array}{c}\text { Alunos } \\
\text { vinculados a } \\
\text { oferta }\end{array}$ & $\begin{array}{c}\text { Atividades } \\
\text { Respondidas }\end{array}$ & $\begin{array}{c}\text { Respostas } \\
\text { Corretas }\end{array}$ \\
\hline $\begin{array}{l}3 \text { cursos } \\
\text { Graduação }\end{array}$ & $\begin{array}{l}\text { Comunicação } \\
\text { Organizacional/Sistema } \\
\text { de Informação }\end{array}$ & 812 & $18 \%$ & $100 \%$ \\
\hline $\begin{array}{l}\text { Cst Gestão } \\
\text { Hospitalar }\end{array}$ & $\begin{array}{l}\text { Hotelaria Hospitalar e } \\
\text { Marketing Hospitalar }\end{array}$ & 480 & $62 \%$ & $85 \%$ \\
\hline $\begin{array}{l}\text { Cst Gestão } \\
\text { em Saúde } \\
\text { Pública }\end{array}$ & $\begin{array}{l}\text { Gestão de contratos e } \\
\text { convênios em serviços } \\
\text { de saúde/Gestão de } \\
\text { recursos Humanos }\end{array}$ & 322 & $45 \%$ & $74 \%$ \\
\hline
\end{tabular}

Fonte: os autores, 2018

Contudo, constata-se que de uma forma geral os alunos estão conseguindo estabelecer um pensamento integrador e apresentar respostas interdisciplinares para a resolução de determinadas situações, pois considerando os 587 alunos que realizaram as atividades obteve-se um índice de $86 \%$ de acertos. Isso demonstra que os cursos pesquisados estão conseguindo trabalhar com seus alunos a interdisciplinaridade, conforme sugestiona a nova tendência do processo ensino-aprendizagem.

\section{CONCLUSÃO}

A interdisciplinaridade apresenta-se como uma necessidade no mercado de trabalho, visto que entre as situações cotidianas é preciso utilizar o conhecimento de várias áreas para apresentar uma solução eficiente. Dessa forma, os cursos de graduação estão buscando cada vez mais estimular os futuros profissionais a estabelecerem esse pensamento integrador.

No presente estudo pode-se verificar que os alunos que compõem as unidades curriculares (UCs) estudadas estão conseguindo estabelecer essa conexão entre os vários saberes e apresentar soluções eficientes que relacionem mais de uma unidade curricular (86\%). Por outro lado, as disciplinas de sistema de informação gerencial e comunicação organizacional foram as UCs que apresentaram maior índice de resposta esperada, logo, conclui-se maior conexão entre os saberes por parte dos discentes (100\%).

Essa conexão e capacidade de unir vários conhecimentos para elaborar uma solução sugere uma maior facilidade de adaptação ao mercado de trabalho. Ao final concluímos que esse tema carece de mais estudos para confirmação dos dados apresentados, o que a equipe de pesquisadores durante os sucessivos anos deverá aprofundar mais os estudos e a relação da interdisciplinaridade no mercado de trabalho como diferencial 
competitivo.

\section{REFERÊNCIAS}

VIEIRA, A.A.N. et al. Metodologia Científica no Brasil: ensino e interdisciplinaridade. Educação \& Realidade, Porto Alegre, v. 42, n. 1, p. 237-260, jan. /mar. 2017.

COSTA, C. A.; LOUREIRO, C.F. A interdisciplinaridade em Paulo Freire: aproximações político-pedagógicas para a educação ambiental crítica. R. Katál., Florianópolis, v. 20, n. 1, p. 111-121 jan. /abr. 2017.

SCHWARTZMAN, U.P.; et al. Interdisciplinaridade: referencial indispensável ao processo de ensino-aprendizagem da bioética. Rev. bioética. (Impr.) v.25, n. 3, p. 536-43, 2017.

XAVIER, A. M.; STEIL, L. J.; MENA-CHALCO, J. P. (Inter)disciplinaridade e transversalidades: o projeto de formação superior da Universidade Federal do ABC. Ciênc. Educ., Bauru, v. 23, n. 2, p. 373-390, 2017.

JAPIASSÚ, H.; MARCONDES, D. Dicionário básico de filosofia. 4. ed. Rio de Janeiro: Zahar, 2006.

FARIAS, D.N. et al. Interdisciplinaridade e Interprofissionalidade na Estratégia Saúde da Família. Trab. Educ. Saúde, Rio de Janeiro, v. 16 n. 1, p. 141-162, jan. /abr. 2018.

PIRES, M.F.C. Multidisciplinaridade, Interdisciplinaridade e Transdisciplinaridade no Ensino. Interface - Comunic, Saúde, Educ 2. São Paulo, fev., 1998.

ROQUETE, F.F., et al. Multidisciplinaridade, Interdisciplinaridade e Transdisciplinaridade: em busca de diálogo entre saberes no campo da saúde coletiva. R. Enferm. Cent. O. Min. v. 2, n. 3, 2012. 